\title{
The effects of repetitive transcranial magnetic stimulation (rTMS) over the motor cortex on complex regional pain syndrome patients
}

Os efeitos da estimulação magnética transcraniana repetitiva (EMTr) aplicada sobre o córtex motor de pacientes com síndrome complexa de dor regional

Helder Picarelli

Faculdade de Medicina da Universidade de São Paulo (2009), São Paulo SP, Brazil.

Área de concentração: Neurologia

Orientador: Prof. Dr. Manoel Jackobsen Teixeira

Correspondence: Helder Picarelli; Rua Itacolomi 333 / conj. 52; 01239-020 São Paulo SP - Brasil; E-mail: helder.picarelli@icesp.org.br

\begin{abstract}
Objective: There are many evidences that repetitive transcranial magnetic stimulation (rTMS) of the motor cortex is effective in relief of chronic pain. The aim of this study was to evaluate the analgesic effects of rTMS in patients with refractory complex regional pain syndrome (CRPS). Methods: Twenty-three patients presenting with CRPS of the hand were randomly selected and treated with conventional treatment (analgesics, adjuvant medications and physical therapy) plus sham-TMS or rTMS to the motor cortex opposite the affected limb: $100 \%$ MT, 10 hz, 10 s trains, 25 trains daily, 10 daily sessions. The Visual Analogical Scale of Pain (VAS), McGill Questionnaire, Pain Impact Questionnaire (PIQ-6), Disabilities of the Arm, Shoulder and Hand Questionnaire (DASH), Hamilton Depression and Anxiety Rating Scales and SF-36 Questionnaire were the instruments used for the evaluation. The groups were comparable with regards to socio-demographics, mood and pain intensity. Evaluations were performed before, during TMS treatment and up to three months the end of the treatment. Results: There was a significant reduction in VAS scores favoring the rTMS group up to the seventh follow-up day $(p<0.05)$. The mean reduction in the rTMS group was of $4.65 \mathrm{~cm}$ (fall of $50.9 \%$ ) against $2.18 \mathrm{~cm}$ (fall of $24.7 \%$ ) in sham group during treatment. Improvement in VAS scores was independent of other variables, except for improvement in emotional aspects in the SF-36. Conclusions: During rTMS sessions, there was significant and positive improvement in pain experience of CRPS patients regardless of mood, function or quality of life effects.
\end{abstract}

Key words: magnetic transcranial stimulation, reflex sympathetic dystrophy, /therapy, complex regional pain syndromes. 